\title{
Identificação e controle de riscos ocupacionais em pedreira da região metropolitana de São Paulo
}

\author{
(Identification and control of occupational \\ risks in a São Paulo metropolitan region \\ quarry)
}

\section{Wilson Siguemasa Iramina}

Engenheiro de Minas e de segurança do trabalho. Professor Associado do

Departamento de Engenharia de Minas e de Petróleo da Escola Politécnica da Universidade de São Paulo.

E-mail:wilson.iramina@poli.usp.br

\section{Ivan Koh Tachibana}

Engenheiro de Minas, Engenheiro de Segurança, Mestrando em Engenharia Mineral da Escola Politécnica da Universidade de São Paulo. E-mail: ivan.tachibana@poli.usp.br

\section{Leonardo Motta Camargo Silva}

Engenheiro de Minas, Engenheiro de Segurança, Gerente da Embu S.A. E-mail:Imotta@embusa.com.br

\section{Sérgio Médici de Eston \\ Professor Titular e Chefe do Departamento de Engenharia de Minas e de Petróleo da Escola Politécnica da \\ Universidade de São Paulo. E-mail:smeston@usp.br}

\section{Resumo}

A mineração de pedra britada é a terceira em movimentação financeira do país, sendo que quase metade da economia desse bem se concentra na região metropolitana de São Paulo. Paralelamente, o setor registrou o maior número de acidentes entre as indústrias extrativas, evidenciando a relevância da preocupação com a saúde e a segurança dos trabalhadores e a importância do controle dos riscos ocupacionais. A partir de 2002, a Norma Regulamentadora 22 (NR-22: Segurança e Saúde Ocupacional na Mineração) tornou obrigatória a elaboração do Programa de Gerenciamento de Risco (PGR), elaborado a partir da identificação e controle dos riscos.

Tendo em vista a importância do setor para o Estado, buscou-se, com esse trabalho, avaliar e discutir os riscos presentes nas operações unitárias do processo produtivo de pedra britada em uma mina a céu aberto e propor medidas de controle para elaboração do PGR. Apesar de esse trabalho referir-se a um caso específico, este pode ser estendido a outras minerações do setor, desde que sejam realizadas as considerações relativas às diferenças nos processos produtivos. $\mathrm{O}$ desenvolvimento da pesquisa envolveu a identificação dos principais riscos associados às operações de perfuração, desmonte, carregamento e transporte, britagem e peneiramento por meio de medições de campo de alguns agentes e relatórios e registros da empresa. Os resultados obtidos foram decisivos para a determinação das medidas de controle adequadas para a melhoria das condições de saúde e segurança dos trabalhadores.

Palavras-chave: Mineração, segurança do trabalho, higiene ocupacional, pedreira.

\section{Abstract}

Crushed stone mining is the third largest mining economy in Brazil, where almost half is produced in the Sao Paulo metropolitan region. The segment registers the highest number of accidents among the extractive industries, which justifies the concern with workers' health and safety and the importance of controlling occupational hazards. Since 2002, the NR-22 Standard (NR-22: 
Occupational Health and Safety in Mining) makes compulsory the elaboration of a Risk Management Program that identifies risks and establishes control measures.

Considering the crushed stone mining industry's importance to the state, this paper evaluates and discusses the risks identified in unit operations during the production process of crushed stone in an open pit mine in order to propose control measures for the development of the Risk Management Program. Although this study refers to a specific quarry, it can be applied to other mines from the same sector, since some considerations are made regarding differences in manufacturing processes. The research was based on the identification of the main risks associated with drilling, blasting, load \& haulage, crushing and screening through field measurements of some hazardous agents, together with company reports. The results contributed to the choice of the appropriate control measures for the improvement of workers' health and safety conditions.

Keywords: Mining, work safety, occupational hygiene, quarry.

\section{Introdução}

A preocupação com a saúde e a segurança do trabalhador no setor de extração mineral tem crescido em função da conscientização de empregadores e empregados, os quais vêm nuscando respeitar às novas legislações, implementando mudanças comportamentais, uma vez que vem aumentando, nos últimos anos, o número de acidentes e doenças ocupacionais.

A mineração de rochas (britadas) e de cascalho movimentou, em 2005, mais de 1,7 bilhões de reais, segundo dados do Departamento Nacional de Produção Mineral (DNPM, 2006), tendo sido a terceira em movimentação financeira. O Estado de São Paulo foi responsável por $43,29 \%$ do consumo de rochas britadas e de cascalhos (R \$ 550 milhões movimentados), sendo a região metropolitana o maior mercado consumidor. Para atender a essa demanda, as empresas empregam milhares de trabalhadores, suscetíveis a acidentes e doenças ocupacionais.

A Figura 1 apresenta o total de acidentes ocorridos no setor de extração de pedra, areia e argila, segundo dados da Previdência Social (Brasil, 2008), demonstrando que o número de acidentes ficou em torno de 1.000/ano entre $2000 \mathrm{e}$
2006. Além disso, esse setor registrou o maior número de acidentes entre as indústrias extrativas, evidenciando a relevância da preocupação com a saúde e com a segurança dos trabalhadores e a importância do controle dos riscos ocupacionais.

O aumento do número de acidentes de trabalho ocorridos em mineração de pedra britada no Brasil chama atenção das autoridades e dos especialistas e, também, dos próprios empreendedores, que passaram a se preocupar com seus trabalhadores. Entre 2000 e 2006, verificou-se um crescimento de $35 \%$ no número de acidentes (de 944 para 1273), dos quais $26 \%$ se deram após 2003. Entretanto o número de acidentes no Estado de São Paulo, em relação ao total nacional, decresceu de 32 para $21 \%$ para o período considerado (de 2000 a 2006).

Dos acidentes ocorridos, aproximadamente, 90\% caracteriza-se como acidente típico, ou seja, ocorrido no ambiente de trabalho, panorama este que se repete tanto no Brasil como no Estado de São Paulo. Apesar de o número de acidentes ter uma tendência de alta, justificada não pelo agravamento da situação, mas pelo maior numero de registros oficiais, proporcionalmente, esses acidentes típicos vêm diminuindo.

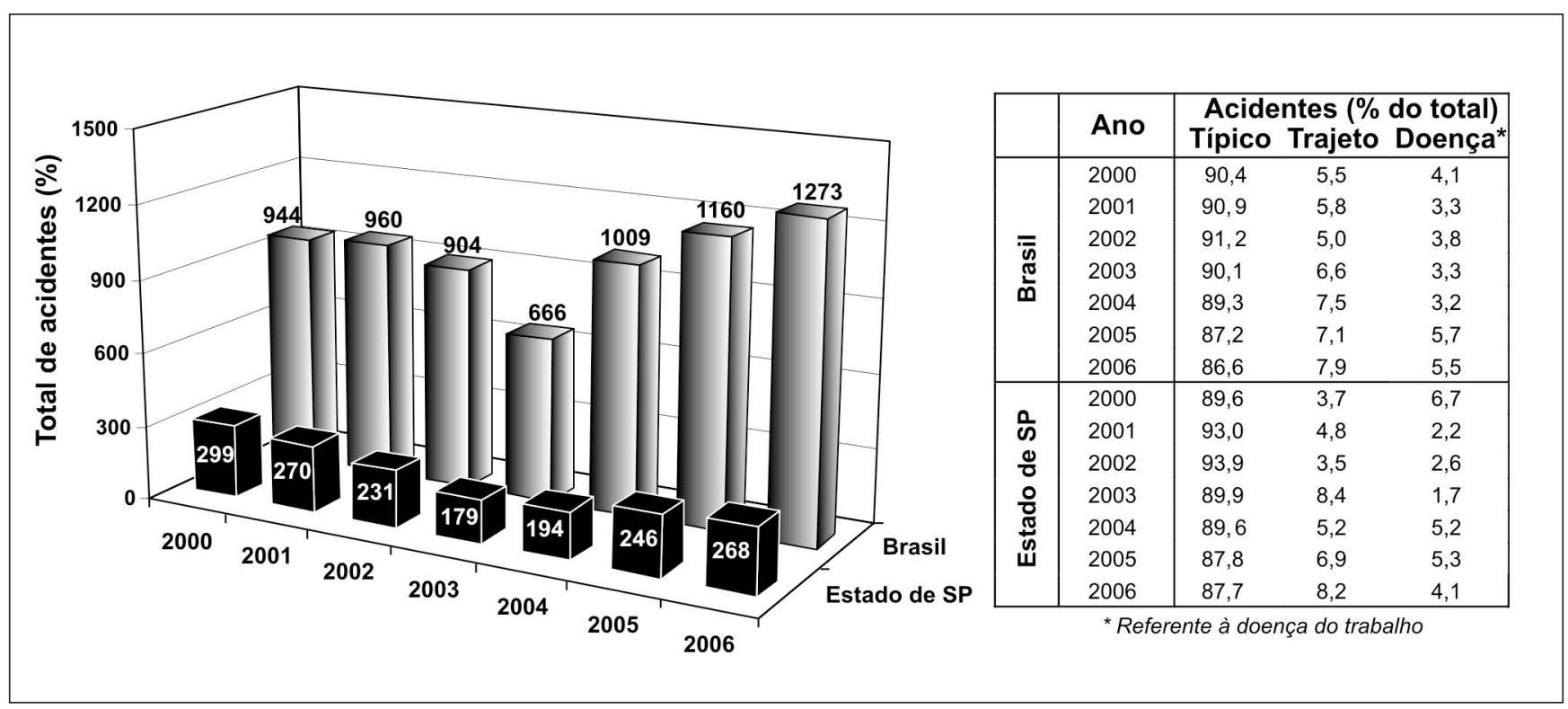

Figura 1 - Número de acidentes do trabalho registrados no setor de extração de pedra, areia e argila. Quadro 1 - Ocorrências de acidentes do trabalho. (Fonte: Brasil, 2008). 
Wilson Siguemasa Iramina et al.

A importância do setor no Estado, somada à significativa movimentação financeira envolvida na atividade, possibilitou um maior investimento, tanto no conhecimento e monitoramento dos riscos, quanto na tomada de medidas de controle.

A mineração apresenta risco grau 4, segundo classificação da Norma Regulamentadora 4 (MTE, 2008), Quadro 1, o que se reflete em uma maior exposição do trabalhador ao risco e na ocorrência de acidentes.

Baseando-se em trabalhos de diversos autores, foram identificados os principais riscos aos quais os trabalhadores estão expostos em uma mineração de pedra britada. São eles:

- Poeira de sílica: pode provocar a silicose, principal doença pulmonar e uma das maiores preocupações ocupacionais (Gruenzner, 2006; Gabas, 2008).

- Ruído: a exposição a níveis elevados sem devida proteção pode causar perdas auditivas irreversíveis (Schrage, 2005).

- Incêndios e explosões: associados a lubrificantes, explosivos e outros materiais combustíveis têm, como consequências, perdas materiais e morte de um ou mais trabalhadores (Iramina, 1996).

- Estabilidade do talude: blocos de rocha podem se desprender dos taludes e atingir veículos e trabalhadores no local.

- Quedas: o trabalho em bancadas com alturas de 10 a 20 metros expõe o trabalhador a possíveis quedas durante sua atividade.

- Acidentes gerais: podem acontecer com os trabalhadores ao lidarem com movimentação de máquinas, elementos móveis (correias), pisos escorregadios e/ou irregulares, produtos e ferramentas durante todo o período de trabalho (Mendes, 2001). Cortes e esmagamento de membros também podem ocorrer em determinadas atividades. Inclui contato com produtos químicos, principalmente na pele e olhos, podendo causar queimaduras e cegueira. Fragmentos de rocha podem atingir os trabalhadores devido à instabilidade dos taludes (Zea Huallanca, 2004).

- Calor: a exposição do trabalhador ao sol pode levar a estresse térmico, queimaduras, desidratação, etc. (Moran et $\mathrm{al}, 2004)$.

- Ergonômicos: presentes na maioria das atividades. As lesões são causadas por má postura e repetição de movimentos, além de esforços excessivos no uso de equipamentos pesados (Mascia, 1997).

- Vibração mecânica: a exposição prolongada pode provocar problemas vasculares, neurológicos, musculares e articulares (Cunha, 2006).

Em virtude da maior conscientização e preocupação das empresas e empregados, o panorama da segurança do trabalho no Brasil tem se alterado, de modo que o que antes era considerado custo, hoje, é visto como investimento. Paralelamente, a legislação específica para mineração está se atualizando e a fiscalização está cada vez mais atuante e rigorosa. Tais fatores contribuem para uma melhoria nas condições de saúde, higiene e segurança no setor.

Uma política de Saúde e Segurança do Trabalho (SST) contribui para o estabelecimento das mudanças e melhorias propostas, já que promove um maior comprometimento da gerência da empresa (Lima, 2002). A Norma Regulamentadora 22 (NR-22: Segurança e Saúde Ocupacional na Mineração) determina a elaboração do Programa de Gerenciamento de Risco (PGR), obrigando as empresas do setor de mineração a agirem de modo preventivo, garantindo, assim, a saúde e a segurança dos trabalhadores (Barreiros, 2002). Dessa forma, a identificação e o controle dos riscos são imprescindíveis para a prevenção e para o PGR.

O objetivo desse trabalho é avaliar e discutir os riscos presentes nas operações unitárias do processo produtivo de pedra britada em uma mina a céu aberto e propor medidas de controle para ela- boração do PGR, mantendo as empresas em acordo com as normas regulamentadoras.

\section{Materiais e métodos}

Esse trabalho foi desenvolvido em uma pedreira na região metropolitana de São Paulo, mas pode ser aplicado a qualquer outra mineração do setor, desde que sejam realizadas as devidas adaptações (em função de diferenças no processo e equipamentos) e desde que tais adaptações sejam conduzidas por profissionais familiarizados e capacitados no processo produtivo.

Os principais riscos associados às operações de perfuração, desmonte, carregamento, britagem e peneiramento foram avaliados por meio de análises de campo, relatórios e registros da empresa e medições de alguns agentes. Para cada um dos riscos identificados, foram propostas medidas de proteção ou correções, de acordo com as novas tecnologias existentes, técnicas propostas em literaturas e experiências de campo.

O fluxograma do processo produtivo está ilustrado na Figura 2.

\section{Resultados e discussões}

Na Tabela 1, é apresentado um sumário dos riscos para as atividades consideradas no processo produtivo.

A poeira é um agente que está presente em todas as atividades, já que a geração de material particulado é intrínseca à produção de pedra britada. A sobrecarga térmica, em atividades a céu aberto, deve-se à exposição dos trabalhadores ao sol durante toda a jornada de trabalho, fato agravado pela à ausência de sistemas de ar condicionado ou ventilação suficiente em grande parte das máquinas. Os problemas ergonômicos ocorrem, principalmente, devido às más posturas na execução das tarefas e à permanência prolongada em uma mesma posição, como no caso dos motoristas de caminhões ou operadores de carregadeiras. 


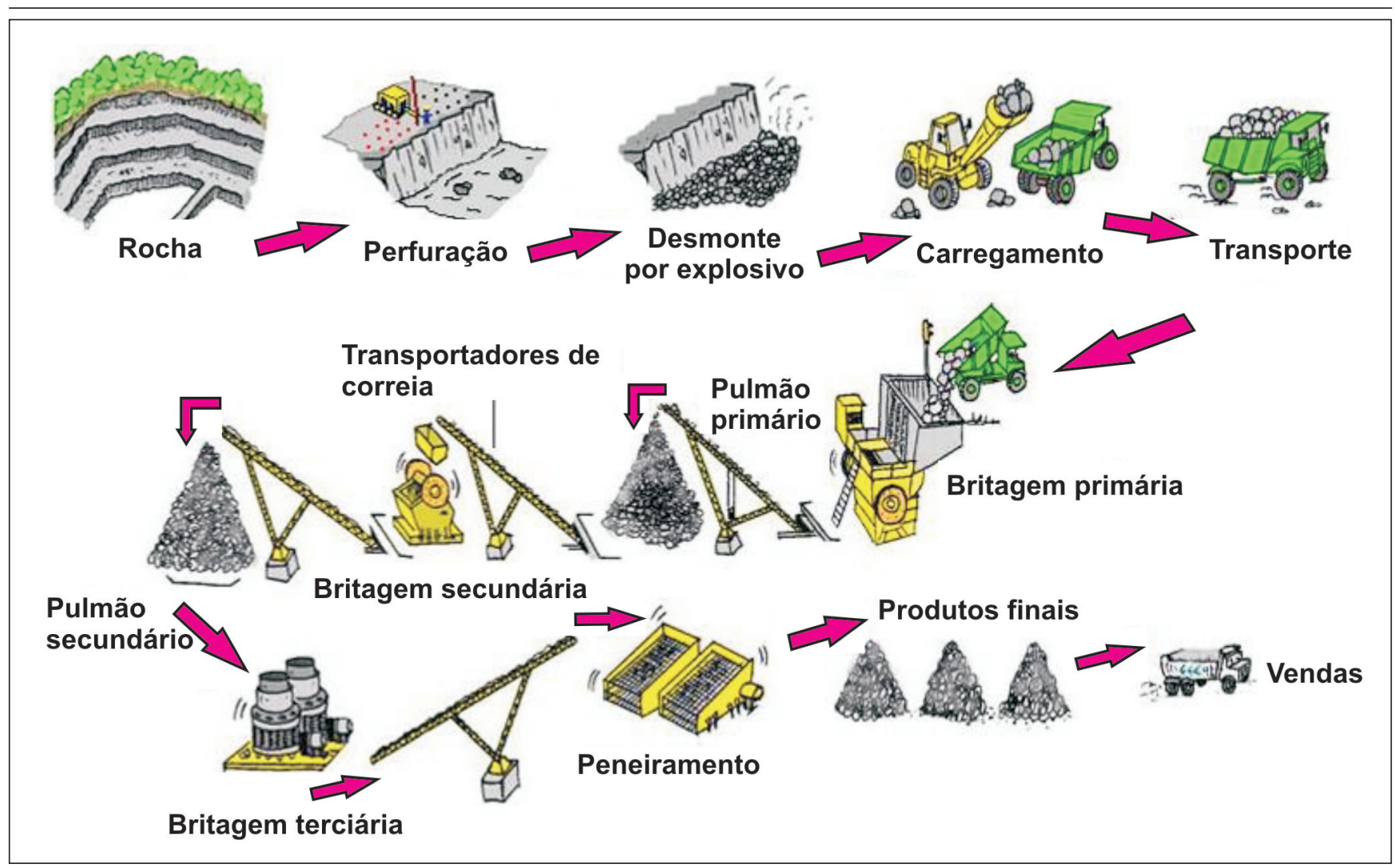

Figura 2 - Fluxograma do processo produtivo.

Tabela 1 - Principais riscos envolvidos nas atividades de uma pedreira.

\begin{tabular}{|c|c|c|c|c|c|c|c|c|}
\hline $\begin{array}{l}\text { Riscos avaliados por atividade, em uma } \\
\text { mineração de pedra britada }\end{array}$ & 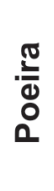 & $\frac{ㅇ ㅡ ㅁ ~}{\frac{0}{3}}$ & 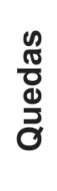 & $\begin{array}{l}\stackrel{0}{\stackrel{0}{c}} \\
\frac{0}{0} \\
\frac{0}{0}\end{array}$ & $\frac{\grave{0}}{\bar{J}}$ & 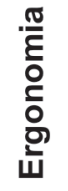 & 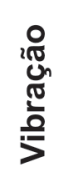 & 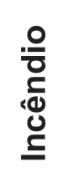 \\
\hline Perfuração de Bancada & $\mathrm{X}$ & $\mathrm{X}$ & $\mathrm{X}$ & $\mathrm{X}$ & $\mathrm{X}$ & $\mathrm{X}$ & $\mathrm{X}$ & $\mathrm{x}$ \\
\hline Carregamento de explosivos e detonação & $\mathrm{X}$ & & $X$ & $\mathrm{X}$ & $\mathrm{X}$ & $\mathrm{X}$ & & $\mathrm{X}$ \\
\hline Carregamento e Transporte de Rocha & $\mathbf{x}$ & $\mathrm{X}$ & & $\mathrm{x}$ & $\mathrm{X}$ & $\mathbf{x}$ & 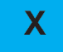 & \\
\hline Britagem e peneiramento & $\mathrm{X}$ & $\mathrm{X}$ & & $\mathrm{X}$ & & $\mathrm{X}$ & $\mathrm{X}$ & $\mathrm{X}$ \\
\hline
\end{tabular}

O processo de perfuração de bancadas expõe o trabalhador a todos os tipos de riscos, principalmente material particulado da rocha e o ruído da perfuratriz, devido à proximidade com que o operador deve trabalhar da fonte geradora de poeira e de ruído. Os riscos ergonômicos e de vibração estão presentes, principalmente, na preparação para o desmonte secundário, com o uso de marteletes pneumáticos. Há risco de incêndios ou mesmo explosões, dada a possibilidade da presença de explosivos remanescentes não detonados no desmonte. Cortes e esmagamentos podem ocorrer durante o manuseio das hastes de perfuração.
O carregamento de explosivos, normalmente, é realizado em bancadas isoladas, afastados da perfuração ou do carregamento e transporte de materiais. Assim, o ruído não é um problema que afeta os trabalhadores. O risco de incêndio e de acidentes em geral está, principalmente, ligado à manipulação de produtos químicos e explosivos. A detona- 
Wilson Siguemasa Iramina et al.

ção, apesar de gerar ruído, não afeta as pessoas, já que é exigida, por medidas de segurança, a permanência a grandes distâncias do ponto de detonação.

No carregamento e transporte de rocha, o ruído e a poeira de sílica estariam dentro dos níveis aceitáveis, se os motoristas dos caminhões mantivessem as janelas fechadas. Essa prática é impossível de ser mantida, principalmente, em função do desconforto térmico, dada a ausência de sistemas condicionadores de ar, o que acarreta exposição dos trabalhadores a esses riscos. A vibração no interior desses veículos é intensa, causando grande desconforto ao motorista e possibilidades de grandes problemas ergonômicos. Quedas de fragmentos de rocha de taludes instáveis ou mesmo atropelamentos podem ocorrer durante a jornada de trabalho.

Os trabalhadores que atuam no setor de britagem e peneiramento, sejam em manutenções preventivas ou preditivas, reparos, trocas de peças, mudanças no processo, ou que circulam pela área, estão expostos aos riscos assinalados na Tabela 1. Nesses casos, acidentes com parte móveis, como polias, também podem ocorrer.

Após as análises de campo e acompanhamento das atividades dos trabalhadores, foram sugeridas as medidas de controle para cada um dos riscos supracitados, expostas na Tabela 2.

Algumas medidas de controle são comuns a todas as atividades e devem ser adotadas nos processos envolvidos na produção de pedra britada. A saber:

- Procedimentos operacionais claros e bem definidos: com tais procedimentos, os trabalhadores têm um padrão elaborado pela gerência, fato que garante uma maior segurança na execução de sua atividade.

- Substituição dos equipamentos e tecnologias por equivalentes mais modernos e seguros: com essa medida,os trabalhadores podem manter-se isolados das fontes emissoras, evitando exposição desnecessária e, conseqüentemente, ficam protegidos dos perigos
Tabela 2 - Medidas de controle propostas para a melhoria das condições de saúde e segurança dos trabalhadores.

\section{Poeira de sílica}

- Instalação de coletores de poeira nas perfuratrizes.

- Umidificação dos processos.

- Enclausuramento das fontes emissoras de material particulado.

- Uso de protetor respiratório.

\section{Ruído}

- Uso de protetor auricular.

- Enclausuramento das fontes emissoras de ruído.

- Uso de máquinas com cabine fechada.

- Construção de cabines de comando das operações de beneficiamento.

- Automação de processos que evitem contato do trabalhador com a fonte.

\section{Quedas}

- Construção de muretas ou obstáculos que evitem a aproximação de beiras de bancadas.

- Uso de cinto de segurança ou talabarte em trabalhos de carregamento de explosivos onde haja risco de quedas.

\section{Acidente}

- Uso de EPI como luvas, botas, capacetes, óculos e cinto de segurança para evitar cortes, esmagamentos, acidentes com produtos químicos.

- Automação de processos.

- Terceirização de processos como fabricação, transporte, armazenamento e manuseio de explosivos.

- Isolamento ou proteção de partes rodantes como polias, roletes e correrias.

- Ter programas de manutenção preventiva e preditiva de veículos e equipamentos.

- Instalação de câmeras de vídeo em locais estratégicos para controle dos processos.

- Substituição de produtos similares mais seguros.

\section{Calor}

- Uso de roupas adequadas e mais leves.

- Uso de máquinas com cabines aclimatadas.

- Utilização de guarda-sol / chuva.

- Descanso em ambientes com temperaturas mais amenas.

\section{Ergonomia}

- Mudanças nos procedimentos evitando más posturas.

- Pausas durante a jornada para alongamentos e mudanças na posição sentada.

\section{Vibração}

- Diminuição do tempo de exposição.

- Mudança ou adaptações nos veículos.

- Melhor manutenção das pistas.

- Não utilização de marteletes pneumáticos.

\section{Incêndio}

- Sistemas de combate a incêndio.

- Terceirização no manuseio e operação de explosivos 
presentes. Um exemplo bem sucedido empregado pela empresa avaliada foi a substituição das perfuratrizes pneumáticas e hidráulicas sem cabines por modelos cabinados. A mudança foi feita após análise dos resultados e medidas propostas nesse trabalho.

Cabe ao engenheiro de segurança e aos demais membros do SESMT (Serviço Especializado em Engenharia de Segurança e Medicina do Trabalho) o gerenciamento de todos os riscos presentes nas diversas atividades de mineração, para que se garanta ao trabalhador um ambiente seguro e saudável.

\section{Análise dos riscos}

É recomendada a aplicação de metodologias para análises de riscos, cabendo ao profissional de segurança e saúde da empresa refinar e implementar o método, adequado-o ao processo produtivo em questão. Essa etapa também é importante para a elaboração do Plano de Gerenciamento de Riscos (PGR), já que indica as prioridades das ações a serem tomadas.

A avaliação de risco, apesar de ser qualitativa, pode ser transformada em uma escala numérica a partir da avaliação da probabilidade de acontecimento e da severidade do risco (metodologia desenvolvida e aplicada por Lapa (2006)). A grande vantagem do método é facilitar a identificação das prioridades das ações que devem ser tomadas.

A metodologia desenvolvida por Lapa, utilizada por diversas empresas do setor de mineração, quantifica o risco através do produto da probabilidade pela severidade. A probabilidade é definida pela soma de quatro variáveis, cada uma com valor atribuído de 1 a 3: freqüência de exposição ao perigo, número de pessoas expostas a esse perigo, eficácia dos meios de controle disponíveis e a facilidade de reconhecimento e identificação prévia do perigo. Já a severidade é definida pela soma de duas variáveis: a gravidade (valores atribuídos de 1 a 9) e a escala de abrangência (valores atribuídos de 1 a 5) da lesão, dano ou doença potencial. Os valores são atribuídos de tal forma que situações diferentes de cada variável têm uma pontuação correspondente, em uma escala pré definida. Ao final, o risco será classificado segundo uma matriz e poderá ser trivial, tolerável, moderado, substancial ou intolerável.

Como exemplo, baseando-se em medições de campo e utilizando a metodologia proposta por Lapa, temos que o risco para ruído, cuja magnitude é de 94,1 dBA, na operação de perfuração pneumática, é de 42 (probabilidade $=7 \mathrm{e}$ severidade $=6$ ). A classe do risco neste caso é moderada, exigindo uma reavaliação da situação, verificando se há possibilidades de melhoria das condições de exposição ao ruído pelo operador. Analogamente, esse procedimento deve ser aplicado a todos os riscos presentes. Das operações analisadas, nenhum risco se mostrou substancial ou intolerável, o que, segundo o autor, exigiria medidas de controle imediatas para levar o risco pelo menos à classe moderada.

Medidas como planejamento durante as etapas de avaliação de riscos e a valoração dos mesmos podem poupar recursos valiosos, sendo que a prioridade deve ser dada aos riscos intoleráveis ou substanciais, secundariamente aos moderados e, finalmente, aos triviais.

Tais medidas demandam tempo, mão-de-obra qualificada e especializada e elevado comprometimento, entretanto, se realizadas adequadamente, são muito efetivas na preservação da segurança e saúde dos trabalhadores, possibilitando a redução do número de acidentes, evitando perdas de produção ou mudanças na rotina de trabalho.

\section{Conclusões}

Nesse trabalho, foram identificados os riscos envolvidos nas etapas de produção de areia e brita e sugeridas algumas medidas de segurança, controle e minimização em cada uma delas. Sugestões de melhorias, como o uso de perfuratrizes cabinadas, a construção da cabine de controle para a britagem e penei- ramento e o uso de câmeras de vídeo, vêm sendo utilizadas na pedreira atualmente, e já foram observados avanços nas condições de trabalho, de acordo com os próprios trabalhadores.

É demonstrado por esse trabalho que a análise de riscos e sugestões de medidas de controle são fundamentais para elaboração do Plano de Gerenciamento de Riscos (PGR), obrigatório pela NR-22. Os resultados desse trabalho podem ser utilizados como base na análise de outras pedreiras, ressaltando-se o fato da necessidade de ajustes para a realidade de cada processo produtivo.

Em muitos casos, o custo é o maior obstáculo para implantação das medidas de controle e investimentos na área de segurança e saúde do trabalhador. Entretanto, com a conscientização dos trabalhadores em relação aos riscos, e o envolvimento da gerência, tais questões podem ser solucionadas a custos relativamente baixos, se comparados às consequências de um acidente de trabalho.

Os investimentos numa política de Segurança e Saúde do Trabalho que elevem a segurança dos trabalhadores e reduzam os riscos à sua saúde são realizados pelas pedreiras, mas, ainda, há um longo caminho a ser percorrido para que os riscos ocupacionais alcancem níveis satisfatórios.

\section{Referências bibliográficas}

BARREIROS, D. Gestão da segurança e saúde no trabalho: estudo de um modelo sistêmico para as organizações do setor mineral.São Paulo: Escola Politécnica da Universidade de São Paulo, 2002. 317p. (Tese de Doutorado).

BRASIL. Ministério da Previdência Social. Informações Estatísticas Gerais da Previdência Social. Disponível em: $<$ http://www.previdenciasocial.gov.br/ p g _ s e c u n d a r i a s / previdencia_social_13.asp $>$. Acesso em: 11 ago. 2008

CUNHA, I. A. Exposição ocupacional à vibração em mãos e braços em marmorarias no município de São Paulo: proposição de procedimento 
Wilson Siguemasa Iramina et al.

alternativo de medição. São Paulo: Escola Politécnica da Universidade de São Paulo, 2006. 153p. (Tese de Doutorado).

DNPM. DEPARTAMENTO NACIONAL DE PRODUÇÃO MINERAL. Anuário Mineral Brasileiro, 2006. Parte I Estatística Brasil. Acesso em: 26 de maio de 2009. Disponível em: http:// w w w.d n p m.gov.br/a s s e t s/ galeriaDocumento/AMB2006/I_2006.pdf

GABAS, G. C. C. Análise crítica dos critérios de seleção de respiradores para particulados em ambientes de mineração. São Paulo: Escola Politécnica da Universidade de São Paulo, 2008. 124p. (Dissertação de Mestrado).

GRUENZNER, G. Avaliação da poeira de sílica: um estudo de caso em uma pedreira na região metropolitana de São Paulo. São Paulo: Escola Politécnica da Universidade de São Paulo, 2006. 93p. (Dissertação de Mestrado).

IRAMINA, W. S. Environmental control and blasting technology in Brazil. Proceedings Swemp'96 Cagliari : DigitaUniversita di Cagliari, 1996.
LAPA, R. P. Metodologia de identificação de perigos e avaliação de riscos ocupacionais. São Paulo: Escola Politécnica da Universidade de São Paulo, 2006. 104p. (Dissertação de Mestrado).

LIMA, C. Q. B. Implantação de modelos de gestão para a segurança e saúde no trabalho: estudo de casos no setor mineral. São Paulo: Escola Politécnica da Universidade de São Paulo, 2002. 139p. (Dissertação de Mestrado).

MASCIA, F. Ergonomia. Gestão de operações: a engenharia de produção a serviço da modernização da empresa São Paulo: Edgard Blucher/Fundação Vanzolini, 1997. Parte de Monografia. p. 165-176.

MENDES, R. Máquinas e acidentes de trabalho. Ministério da Previdência e Assistência Social. Coleção Previdência social, v. 13. Brasília, 2001. 86p.

MINISTÉRIO DO TRABALHO E EMPREGO. Normas Regulamentadoras. Disponível em: http://www.mte.gov.br/legislacao/normas_regulamentadoras/default.asp. Acesso em: 11 ago. 2008

MORAN, D. S., PANDOLF, K. B., VITALIS, A., HELED, Y., PARKER, R., GONZALEZ, R. R. The role of solar and UV radiation in environmental stress assessment. Journal of Thermal Biology, v. 29, p. 529-533, 2004

SCHRAGE, M. W. Mapa de ruído como ferramenta de diagnóstico do conforto acústico da comunidade. São Paulo: Escola Politécnica da Universidade de São Paulo, 2005. 101p. (Dissertação de Mestrado).

SEGURANÇA E MEDICINA DO TRABALHO. Manuais de Legislação Atlas. 61 ed. São Paulo: Atlas, 2007

ZEA HUALLANCA, R. E. Mecanismos de ruptura em taludes altos de mineração a céu aberto. São Carlos: Escola de Engenharia de São Carlos, 2004. 124p. (Dissertação de Mestrado).

Artigo recebido em 03/09/2008 e aprovado em 24/08/2009.

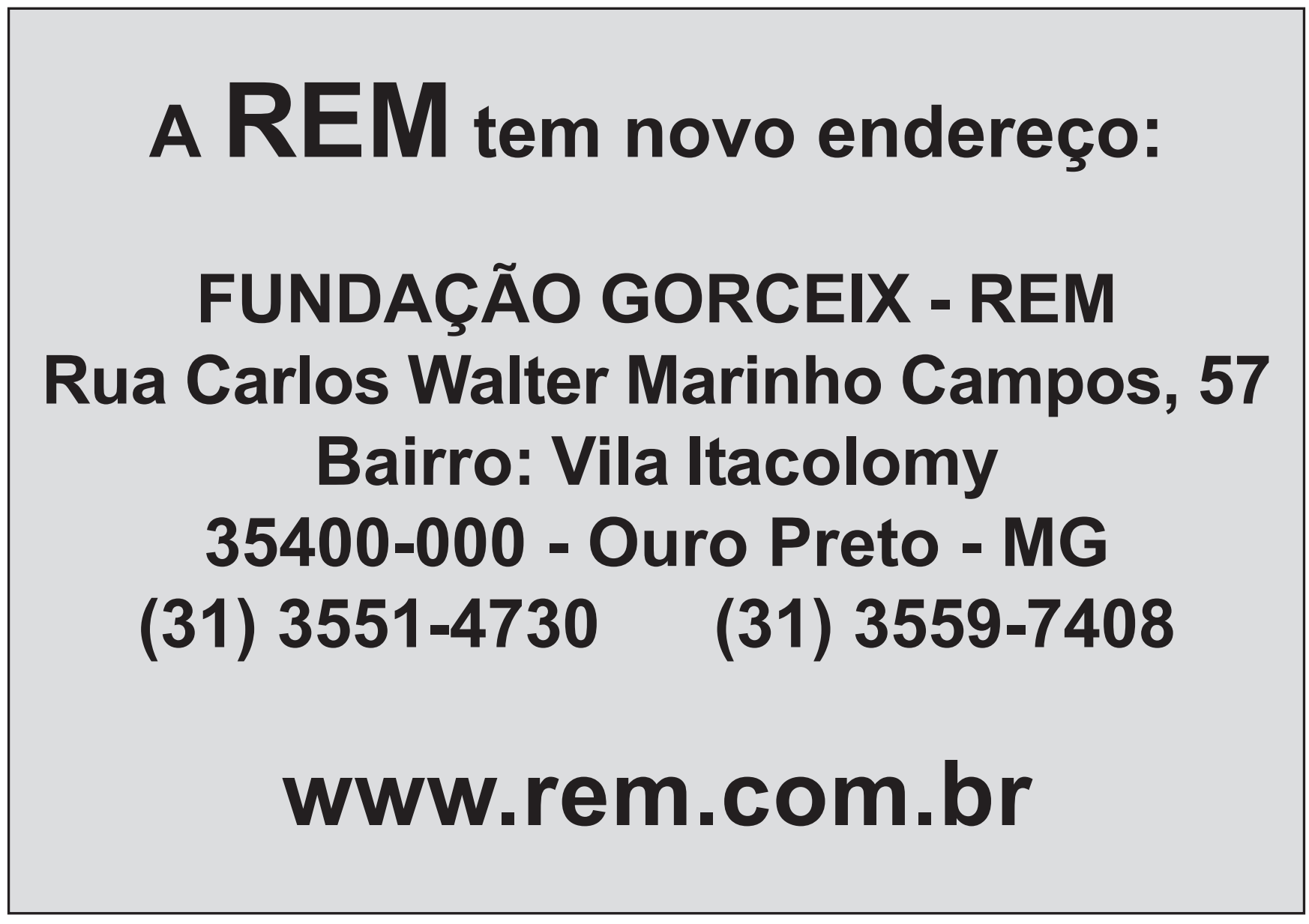

